\title{
Molecular detection of circulating tyrosinase mRNA: Optimization in a preclinical xenograft mouse melanoma model and further evaluation in samples from advanced melanoma patients
}

\author{
MARIANO R. GABRI ${ }^{1 *}$, VALERIA VAZQUEZ ${ }^{1 *}$, SANTIAGO GIRÓN ${ }^{1}$, \\ MÓNICA A. CASTRO ${ }^{2}$, GABRIELA CINAT ${ }^{2}$, ROBERTO E. GOMEZ ${ }^{3}$, \\ FEDERICO M. SANTORO ${ }^{3}$, DANIEL E. GOMEZ ${ }^{1}$ and DANIEL F. ALONSO ${ }^{1}$ \\ ${ }^{1}$ Laboratory of Molecular Oncology, Quilmes National University; ${ }^{2}$ Institute of Oncology \\ 'Angel H. Roffo', University of Buenos Aires; ${ }^{3}$ Elea Laboratories, Buenos Aires, Argentina
}

Received December 17, 2007; Accepted February 1, 2008

\begin{abstract}
We designed high-affinity primers for the mRNA sequence of human tyrosinase to test the value of molecular detection of circulating melanoma cells by reverse transcription-polymerase chain reaction (RT-PCR). The optimization process included in vitro settings and in vivo studies in a xenograft mouse model. We detected tyrosinase expression with at least $40 \mathrm{pg}$ and $1.5 \mathrm{pg}$ of total RNA extracted from cultured SKmel human melanoma cells, using a first round of PCR amplification and nested PCR, respectively. Human tyrosinase expression was found in the blood of nude mice bearing subcutaneous SKmel tumors, and the expression bands were stronger after manipulation of the tumor mass. We also examined the fate of circulating melanoma cells in the present melanoma model. Tyrosinase expression declined in blood $6 \mathrm{~h}$ after a direct intravenous injection of SKmel cells. A preliminary study in human blood samples demonstrated a baseline positive tyrosinase determination in $64 \%(16 / 25)$ of advanced melanoma patients using the RT-PCR nested assay. Baseline tyrosinase expression was significantly associated with disease progression after 12 months, and sequential determination during follow-up of the remaining disease-free patients showed a progressive increase of negative results.
\end{abstract}

Correspondence to: Dr Daniel Alonso, Laboratory of Molecular Oncology, Department of Science and Technology, Quilmes National University, R. Saenz Peña 352, Bernal B1876BXD Buenos Aires, Argentina

E-mail: dfalonso@unq.edu.ar

${ }^{*}$ Contributed equally

Key words: tyrosinase, reverse transcription-polymerase chain reaction, residual cancer, melanoma

\section{Introduction}

Minimal residual disease is defined by microscopic tumor remnants persisting after treatment that can cause disease recurrence. It is detectable only with highly sensitive molecular or cytometric methods (1). The molecular detection of residual disease by reverse transcription-polymerase chain reaction (RT-PCR) of specific target sequences has been proposed as a prognostic tool in different cancers (2). Melanoma was the first tumor variant tested by RT-PCR to show circulating tumor cells in peripheral blood (3). A number of target sequences have been proposed for the detection of residual melanoma, but tyrosinase appears as the most robust marker of melanocyte lineage $(1,4)$.

Over the last few years several studies were conducted to address the prognostic significance of RT-PCR in melanoma progression, with some conflicting results (5-14). Recently, Mocellin et al conducted an encouraging statistical metaanalysis involving 5,433 melanoma patients and concluded that molecular detection might be valuable as a powerful prognostic marker (15). Other studies have also supported the idea that tyrosinase determination in advanced melanoma patients can predict response to therapy $(16,17)$.

Differences between studies may be the consequence of non-standardized RT-PCR procedures. In this sense, the lack of standardization leads to under-optimized molecular detection protocols. Our goal was to shed some light on the controversial validation of tyrosinase expression as a marker of residual disease. We designed novel high-affinity primers for the human tyrosinase sequence with latest generation software, and then used an optimization protocol including both in vitro and in vivo preclinical validation, prior to the evaluation of samples from advanced melanoma patients.

\section{Materials and methods}

Tumor cells. The human melanoma cell line SKmel-28 was maintained in DMEM-F12 culture medium (Gibco BRL) containing $10 \%$ heat-inactivated fetal bovine serum. B16F0 
mouse melanoma, F3II mouse mammary carcinoma, MCF-7 human breast carcinoma and HeLa human cervical carcinoma cells were cultured in the same conditions, with the exception of the addition of $0.01 \mathrm{mg} / \mathrm{ml}$ bovine insulin (Beta Lab, Argentina) in MCF-7 cultures.

Nude mice. Specific pathogen-free athymic nude $(\mathrm{nu} / \mathrm{nu})$ $\mathrm{Balb} / \mathrm{c}$ mice were purchased from the Animal Facility of UNLP (Argentina), and maintained in sterile isolated conditions. Mice were kept 5-10 per cage with water and food ad libitum. Animals with an age of 8-14 weeks and an average weight of $25 \mathrm{~g}$ were used. All animal protocols were supervised and managed by qualified trained personnel according to international guidelines for animal care.

Animal protocols. For tumor cell challenges, SKmel cells were trypsinized, washed with phosphate-buffered saline, re-suspended in serum-free medium, and injected in the nude mice. Melanoma tumors were developed by the subcutaneous injection of $2 \times 10^{6}$ cells, and some mice were experimentally manipulated 20-25 days after challenge in order to promote tumor cell spread, as described in detail (18). Briefly, we applied control pressures of $0.5 \mathrm{~kg} / \mathrm{cm}^{2}$ during a 2-min period on the tumor mass when tumor volume reached around $750 \mathrm{~mm}^{3}$. To inoculate tumor cells into the circulation, $2 \times 10^{5} \mathrm{SKmel}$ cells were injected into the lateral tail vein. Blood samples were obtained from mice 1-24 h after subcutaneous tumor manipulation or intravenous tumor cell injection, with the aim of assessing the presence of circulating melanoma cells by tyrosinase detection.

To confirm the expression of the human melanoma markers S-100 and HMB45, formalin-fixed specimens from SKmel tumors grown in nude mice were processed using the usual paraffin technique and commercial monoclonal antibodies, followed by the immunohistochemical Vectastain ABC Kit (Vector).

Blood sample collection from mice and RNA extraction. Samples of $1 \mathrm{ml}$ of mouse blood were collected and mixed with 1.5 volumes of a stabilization buffer containing $6 \mathrm{M}$ guanidinium thiocyanate, $37.5 \mathrm{mM}$ sodium citrate and $0.75 \%$ $\mathrm{N}$-laurylsarcosine. TRIzol LS solution (Invitrogen) was added according to the manufacturer's recommendations, and RNA precipitation with isopropilic alcohol was made in the resulting aqueous solution. The obtained RNA was solubilized in diethylpyrocarbonate-treated water. In a number of the experiments, RNA was also obtained from fresh tumor samples using a similar extraction procedure.

$R T-P C R$ assay. High-affinity primers for the mRNA sequence of human tyrosinase were designed using PrimeSelect software (DNAStar Inc.). Primers used were: forward, 5'-TGG CGG GAT GCA GAA AAG TGT-3' and reverse, 5'-AGG CAT CCG CTA TCC CAG TAA GTG-3' for PCR, and forward, 5'-GCC CAG CAT CAT TCT TCT CCT CTT G-3' and reverse, 5'-AGC CTT GGG GTT CTG GAT TTG TCA T-3' for nested PCR. First-round primers amplified a sequence between exons 1 and 3 to give a 361-bp product length using the mRNA as a template at $57.1^{\circ} \mathrm{C}$ annealing temperature with 60 cycles of amplification. For nested-PCR the product length was $145 \mathrm{bp}$ at $58.1^{\circ} \mathrm{C}$ annealing temperature with 30 cycles of amplification. In order to test integrity of the RNA, RT-PCR parallel assays were performed using the house-keeping gene glycerol 3-phosphate dehydrogenase (GAPDH) (forward, 5'-GGG GAG CCA AAA GGG TCA TCA TCT-3'; reverse, 5'-GAC GCC TGC TTC ACC ACC TTC TTG-3'), amplifying a 457-bp fragment. PCR products were analyzed by electrophoresis on $2 \%$ agarose gels followed by SYBR Green staining.

Human blood samples. Blood samples from 8 healthy donors and 25 patients with disease-free advanced melanoma (stage III or IV, according to AJCC guidelines) were obtained and processed for tyrosinase detection. Patients were included in an immunotherapy protocol approved by the National Administration for Medications, Food and Medical Technologies (ANMAT, Argentina). Written informed consent was obtained from all patients. Five milliliters of blood were obtained in all cases, and collected in $7.5 \mathrm{ml}$ of the stabilization buffer. Baseline samples were obtained after surgical treatment, and then sampling was performed every 3 months for up to 1 year. Samples were stored at $-70^{\circ} \mathrm{C}$ until RNA extraction and nested RT-PCR procedure, as described above. Tyrosinase status did not influence the therapeutic decision or the follow-up schedule.

\section{Results}

We first determined the sensitivity and specificity of the RTPCR assay by analyzing serially reduced amounts of RNA obtained from SKmel human melanoma cells, as well as from other tumor cell lines. As shown in Fig. 1A, we detected tyrosinase mRNA with at least $40 \mathrm{pg}$ of total RNA from SKmel cells using outer primers alone. The sensitivity was greatly improved by an additional amplification with nested primers, and $1.5 \mathrm{pg}$ of total RNA, equivalent to less than one melanoma cell, was detected (Fig. 1A). As expected, no tyrosinase expression was detected in human or mouse carcinoma cells, even with the use of higher amounts of total RNA. Notably, no tyrosinase mRNA was revealed in the mouse B16 melanotic melanoma with this RT-PCR assay, indicating the species-specificity for the human target sequence (Fig. 1B). Sequence analysis of RT-PCR products amplified from SKmel cells showed an extensive homology $(>96 \%)$ to the corresponding human tyrosinase fragment (data not shown).

We then evaluated the value of molecular detection of circulating melanoma cells using a preclinical xenograft mouse model. Nude mice inoculated in the subcutis with SKmel human melanoma cells developed tumors with a latency of $7 \pm 1$ days and a growth rate of about $120 \mathrm{~mm}^{3} /$ day. Tumors showed a melanoma-like histology, and positive expression of the melanoma markers S-100 and HMB45 (Fig. 2A). In addition, tyrosinase expression was confirmed in SKmel tumors by the RT-PCR assay (Fig. 2B). As shown in Fig. 3, we detected circulating melanoma cells in blood samples from nude mice either injected intravenously with viable SKmel cells or bearing SKmel subcutaneous tumors. Tyrosinase expression in blood was found both in manipulated and non-manipulated mice, although the bands were 

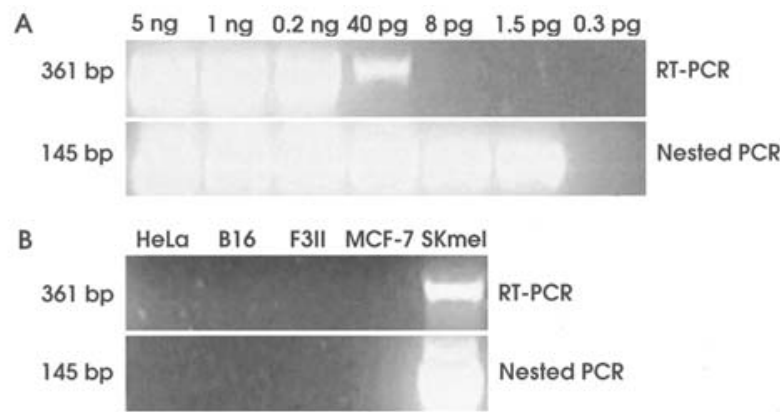

Figure 1. In vitro sensitivity and specificity of the RT-PCR assay. (A) Detection of human tyrosinase mRNA in serially decreasing amounts of total RNA obtained from SKmel melanoma cells using a single round of PCR amplification or nested PCR. (B) Absence of expression of the human target sequence in B16 mouse melanoma, F3II mouse mammary carcinoma, MCF-7 human breast carcinoma and HeLa human cervical carcinoma cells, using $5 \mathrm{ng}$ of total RNA as template. In all cases, RNA integrity was checked by RT-PCR with primers for GAPDH mRNA. PCR products were analyzed by electrophoresis on $2 \%$ agarose gels followed by SYBR Green staining. For experimental details see Materials and methods.

A

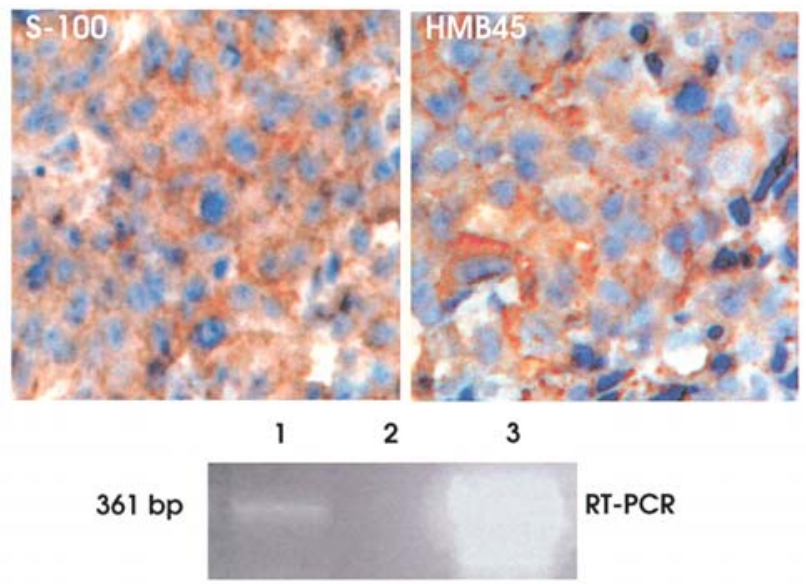

Figure 2. (A) Immunohistochemical detection of the human melanoma markers S-100 and HMB45 in paraffin-embedded material from a subcutaneous SKmel tumor (original magnification x400). (B) Tyrosinase expression tested by RT-PCR. Lane 1, RNA extracted from an SKmel tumor grown in nude mice; lane 2, negative control (without template); lane 3, positive control (SKmel cultured cells).

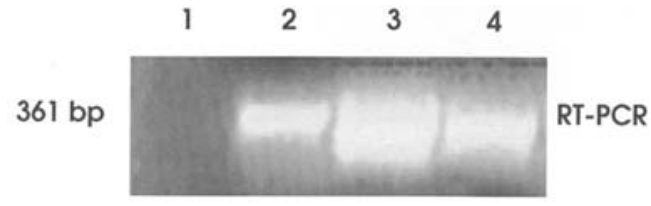

Figure 3. Detection of circulating human melanoma cells in the xenograft nude mouse model. Lane 1, control animals; lane 2, SKmel tumor-bearing animals; lane 3, manipulated SKmel tumor-bearing animals; lane 4, SKmel intravenously injected animals. Blood samples were obtained within 30-60 min after subcutaneous tumor manipulation or intravenous tumor cell injection. Results are representative of at least 3 independent experiments, using blood samples either from individual mice or pooled from 2-5 mice per group. For experimental details see Materials and methods.

stronger after manipulation of the tumor mass. We also examined the fate of circulating melanoma cells in the present xenograft mouse model using the RT-PCR assay. As

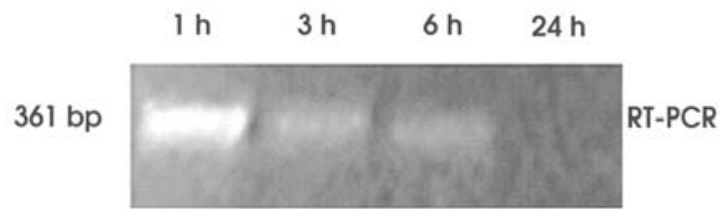

Figure 4. Depletion kinetics of circulating SKmel human melanoma cells in the xenograft mouse model, as determined by the RT-PCR assay. Blood samples from individual mice were obtained at different times after intravenous tumor cell injection, and human tyrosinase mRNA was detected. Results are representative of at least 3 independent experiments.

Table I. Tyrosinase baseline results using reverse transcription followed by nested PCR and disease progression in stage III-IV (AJCC) melanoma patients.

Tyrosinase

baseline status

Patients with progressive disease after 12 months (no.)

\begin{tabular}{llc}
\hline Negative $(\mathrm{n}=9)$ & $44 \%$ & $(4)$ \\
Positive $(\mathrm{n}=16)$ & $87 \%$ & $(14)^{\mathrm{a}}$
\end{tabular}

${ }^{\mathrm{a}} \mathrm{p}=0.02, \chi^{2}$.

Table II. Tyrosinase results using reverse transcription followed by nested PCR during follow-up of the remaining disease-free stage III-IV (AJCC) melanoma patients.

Time of sampling

Patients with positive tyrosinase determination (no./total)

\begin{tabular}{lrc}
\hline Baseline & $64 \%$ & $(16 / 25)$ \\
Month 3 & $43 \%$ & $(9 / 21)^{\mathrm{a}}$ \\
Month 6 & $33 \%$ & $(4 / 12)^{\mathrm{a}}$ \\
Month 9 & $28 \%$ & $(2 / 7)^{\mathrm{a}}$ \\
Month 12 & $0 \%$ & $(0 / 5)^{\mathrm{a}}$ \\
\hline
\end{tabular}

${ }^{\mathrm{a}} \mathrm{p}=0.003, \chi^{2}$ for trend during time.

shown in the depletion kinetics study, tyrosinase expression in blood declined $6 \mathrm{~h}$ after a direct intravenous injection of SKmel cells (Fig. 4).

We further tested blood samples from 25 advanced melanoma patients to preliminarily examine the clinical value of the present RT-PCR assay in detecting viable circulating melanotic cells. Tyrosinase mRNA was detected in $12 \%(3 / 25)$ and $64 \%(16 / 25)$ of baseline samples using a single PCR round and nested PCR, respectively, confirming a significantly higher sensitivity for the nested PCR $(p<0.001$, $\chi^{2}$ ). After 12 months of follow-up, a significantly higher percentage of patients with a positive baseline tyrosinase determination using nested PCR, showed disease progression (Table I). In addition, sequential tyrosinase determination during follow up of the remaining disease-free patients showed a progressive increase of negative results (Table II). 
In all cases, RNA integrity was checked by RT-PCR with primers for GAPDH mRNA. None of the samples from 8 healthy controls gave positive results for tyrosinase.

\section{Discussion}

Tyrosinase is an enzyme that plays a role in the biosynthesis of melanin and is specifically expressed by melanocytes and melanoma cells. Melanocytes do not normally circulate, thus the detection of tyrosinase transcripts in the peripheral blood is considered evidence of intact circulating melanoma cells. Since the original description of the detection of tyrosinase transcripts in peripheral blood by Smith et al (3), results have been reported in terms of the sensitivity of this method and its clinical relevance with conflicting, but mostly positive, findings.

The use of single versus multiple markers detected by RT-PCR was discussed by Taback et al (19). The majority of these studies investigated tyrosinase as a single marker, whereas other studies used multiple markers, including tyrosinase, MelanA/MART1 and gp100, among others. However, there is no uniform consensus that multimarker assays may differ in diagnostic relevance as compared with single tyrosinase mRNA detection (20). Wascher et al (21) investigated a multimarker RT-PCR assay in stage III melanoma patients at high risk of recurrence and death receiving an allogeneic melanoma cell vaccine. They demonstrated that the presence of at least one positive melanoma-specific marker was associated with an increased risk of disease recurrence and a decreased risk of survival.

The reasons for the discrepancies among the reports are difficult to clarify, related perhaps to the patient populations. Szenajch et al (22) showed that patients with a more advanced disease stage more frequently test positive for tyrosinase, which is in line with our results. Most tyrosinase studies including patients in all different melanoma stages have failed in the validation of this marker $(11,23,24)$. However, at this stage it seems that baseline tyrosinase detection has a prognostic value in advanced melanoma patients (stage III and IV) $(16,25)$, the patient population which is the focus of our study. In addition, we showed that sequential tyrosinase determination during follow-up evidenced a progressive increase of negative results. These results are in agreement with the recent study of Quaglino et al (16), suggesting a clearance of circulating melanoma cells in disease-free patients.

To investigate the reliability of RT-PCR assays, an interlaboratory quality assurance study performed by the European Organization for Research and Treatment of Cancer (EORTC) Melanoma Group presented mandatory recommendations, especially rigorous quality control on a per-sample basis when applying RT-PCR assays in clinical trials (26). Previous investigations have indirectly suggested that all steps of sample handling until the completion of cDNA synthesis contribute to the heterogeneity of results and that in contrast, the PCR amplification itself is a rather robust procedure. Hence, RNA quality becomes a key factor for the success of this technique. In our study, the expression of GAPDH was detected in all samples, thus testifying to the integrity of the cDNA preparations. As a result of optimized primer design, we were able to detect very small amounts of the specific tyrosinase mRNA using nested PCR, needing an amount of total RNA equivalent to less than one melanoma cell. The sensitivity achieved with our primer design seems to be superior to that already reported in the literature (3).

Besides the EORTC recommendations (26), we included in vivo studies with human melanoma cells before testing patient samples. We used the SKmel xenograft model as an internal control and, after a classical optimization method of RT-PCR, tyrosinase mRNA detection was possible in the blood of tumor-bearing animals.

The available models of metastasis using human cancer cell lines are limited due to the modest metastatic ability in immunodeficient mice (27). However, a number of studies have described models of tumor invasion and metastatic spread of human cancer cells in nude mice, including melanoma (28-32). Our set of experiments was focused on the determination of circulating malignant cells rather than on their metastatic potential. In this regard, few studies using RT-PCR have focused on the kinetics of shedding of cancer cells from the primary tumor or after a direct intravenous injection. The presence of circulating melanoma cells seems to be transient. As a result of interactions with host tissues, it appears that some tumor cells are killed relatively slowly, over minutes or hours by various arms of the inflammatory and/or immunologic response (33), whereas others are killed rapidly over seconds by mechanical damage (34). Any single measurement in patients may miss the presence of cancer cells, therefore making a positive result a strong indicator of potential disease progression.

Since the usefulness of RT-PCR in predicting the presence of residual melanoma is under debate, especially regarding the lack of standardized procedures (26), we developed sequential in vitro and in vivo preclinical validations to improve the optimization of the detection system. Our data indicate that the molecular detection of circulating tyrosinase mRNA in advanced melanoma patients could be considered a prognostic parameter.

Additional studies will clarify the clinical utility of the present assay by assessing overall survival in a larger series of patients using the same standardized procedure.

\section{Acknowledgments}

M.R. Gabri, D.E. Gomez and D.F. Alonso are members of CONICET. This work was supported by Quilmes National University, Elea Laboratories and grant PID 0343/03 from ANPCYT (Argentina).

\section{References}

1. Mocellin S, Keilholz U, Rossi CR and Nitti D: Circulating tumor cells: the 'leukemic phase' of solid cancers. Trends Mol Med 12: 130-139, 2006.

2. Lacroix $\mathrm{J}$ and Doeberitz MK: Technical aspects of minimal residual disease detection in carcinoma patients. Semin Surg Oncol 20: 252-264, 2001.

3. Smith B, Selby P, Southgate J, Pittman K, Bradley C and Blair GE: Detection of melanoma cells in peripheral blood by means of reverse transcriptase and polymerase chain reaction. Lancet 338: 1227-1229, 1991.

4. Medic S, Pearce RL, Heenan PJ and Ziman M: Molecular markers of circulating melanoma cells. Pigment Cell Res 20: 80-91, 2007. 
5. Visus C, Andres R, Mayordomo JI, Martinez-Lorenzo MJ, Murillo L, Saez-Gutierrez B, Diestre C, Marcos I, Astier P, Godino J, Carapeto-Marquez de Prado FJ, Larrad L and Tres A: Prognostic role of circulating melanoma cells detected by reverse transcriptase-polymerase chain reaction for tyrosinase mRNA in patients with melanoma. Melanoma Res 17: 83-89, 2007.

6. Tatlidil C, Parkhill WS, Giacomantonio CA, Greer WL, Morris SF and Walsh NM: Detection of tyrosinase mRNA in the sentinel lymph nodes of melanoma patients is not a predictor of shortterm disease recurrence. Mod Pathol 20: 427-434, 2007.

7. Mitropapas G, Nezos A, Halapas A, Pissimissis N, Lembessis P, Sourla A, Vassilopoulos P and Koutsilieris M: Molecular detection of tyrosinase transcripts in peripheral blood from patients with malignant melanoma: correlation of PCR sensitivity threshold with clinical and pathologic disease characteristics. Clin Chem Lab Med 44: 1403-1419, 2006.

8. Carrillo E, Prados J, Marchal JA, Boulaiz H, Martinez A, Rodriguez-Serrano F, Caba O, Serrano S and Aranega A: Prognostic value of RT-PCR tyrosinase detection in peripheral blood of melanoma patients. Dis Markers 22: 175-181, 2006.

9. Scoggins CR, Ross MI, Reintgen DS, Noyes RD, Goydos JS, Beitsch PD, Urist MM, Ariyan S, Davidson BS, Sussman JJ, Edwards MJ, Martin RC, Lewis AM, Stromberg AJ, Conrad AJ, Hagendoorn L, Albrecht J and McMasters KM: Prospective multi-institutional study of reverse transcriptase polymerase chain reaction for molecular staging of melanoma. J Clin Oncol 24: 2849-2857, 2006

10. Glumac N, Snoj M, Hocevar M and Novakovic S: Prognostic significance of tyrosinase mRNA detected by nested RT-PCR in patients with malignant melanoma. Neoplasma 53: 9-14, 2006.

11. Ranieri JM, Wagner JD, Wiebke EA, Azuaje R, Smith ML, Wenck S, Daggy J and Coleman JJ III: Lack of prognostic importance of reverse-transcriptase polymerase chain reaction detection of circulating messenger RNA in patients with melanoma. Plast Reconstr Surg 115: 1058-1063, 2005.

12. Quaglino P, Savoia P, Osella-Abate S and Bernengo MG: RTPCR tyrosinase expression in the peripheral blood of melanoma patients. Expert Rev Mol Diagn 4: 727-741, 2004.

13. Schmidt H, Sorensen BS, Sjoegren P, Christensen IJ, Fode K, Larsen J, Nexo E, and von der Maase H.: Circulating tyrosinase and MART-1 mRNA does not independently predict relapse or survival in patients with AJCC stage I-II melanoma. J Invest Dermatol 126: 849-854, 2006.

14. Quaglino P, Osella-Abate S, Savoia P, Bernengo MG, Cappello N and Cavallo $F$ : What is the role of sequential reversetranscriptase polymerase chain reaction analysis of melanomaspecific mRNA in the peripheral blood of melanoma patients? J Clin Oncol 25: 1140-1141, 2007.

15. Mocellin S, Hoon D, Ambrosi A, Nitti D and Rossi CR: The prognostic value of circulating tumor cells in patients with melanoma: a systematic review and meta-analysis. Clin Cancer Res 12: 4605-4613, 2006.

16. Quaglino P, Osella-Abate S, Cappello N, Ortoncelli M, Nardo T, Fierro MT, Cavallo F, Savoia P and Bernengo MG: Prognostic relevance of baseline and sequential peripheral blood tyrosinase expression in 200 consecutive advanced metastatic melanoma patients. Melanoma Res 17: 75-82, 2007.

17. Schmidt H, Sorensen BS, Fode K, Nexo E and von der Maase H: Tyrosinase messenger RNA in peripheral blood is related to poor survival in patients with metastatic melanoma following interleukin-2-based immunotherapy. Melanoma Res 15: 409-416, 2005.

18. Giron S, Tejera AM, Ripoll GV, Gomez DE and Alonso DF: Desmopressin inhibits lung and lymph node metastasis in a mouse mammary carcinoma model of surgical manipulation. $\mathbf{J}$ Surg Oncol 81: 38-44, 2002.

19. Taback B, Morton DL, O'Day SJ, Nguyen DH, Nakayama T and Hoon DS: The clinical utility of multimarker RT-PCR in the detection of occult metastasis in patients with melanoma. Rec Results Cancer Res 158: 78-92, 2001.
20. Kammula US, Ghossein R, Bhattacharya S and Coit DG: Serial follow-up and the prognostic significance of reverse transcriptase-polymerase chain reaction-staged sentinel lymph nodes from melanoma patients. J Clin Oncol 22: 3989-3896, 2004.

21. Wascher RA, Morton DL, Kuo C, Elashoff RM, Wang HJ, Gerami M and Hoon DS: Molecular tumor markers in the blood: early prediction of disease outcome in melanoma patients treated with a melanoma vaccine. J Clin Oncol 21: 2558-2563, 2003.

22. Szenajch J, Jasinski B, Synowiec A, Kulik J, Chomicka M, Struzyna J, Nowecki Z, Rutkowski P, Ruka W, Kupsc W, Siedlecki JA and Wiktor-Jedrzejczak W: Prognostic value of multiple reverse transcription-PCR tyrosinase testing for circulating neoplastic cells in malignant melanoma. Clin Chem 49: 1450-1457, 2003

23. Mangas C, Hilari JM, Paradelo C, Rex J, Fernandez-Figueras MT, Fraile M, Alastrue A and Ferrandiz C: Prognostic significance of molecular staging study of sentinel lymph nodes by reverse transcriptase-polymerase chain reaction for tyrosinase in melanoma patients. Ann Surg Oncol 13: 910-918, 2006.

24. Palmieri G, Ascierto PA, Perrone F, Satriano SM, Ottaiano A, Daponte A, Napolitano M, Caraco C, Mozzillo N, Melucci MT, Cossu A, Tanda F, Gallo C, Satriano RA and Castello G: Prognostic value of circulating melanoma cells detected by reverse transcriptase-polymerase chain reaction. J Clin Oncol 21: 767-773, 2003.

25. Carrillo E, Prados J, Marchal JA, Boulaiz H, Martinez A, Rodriguez-Serrano F, Caba O, Serrano S and Aranega A. Prognostic value of RT-PCR tyrosinase detection in peripheral blood of melanoma patients. Dis Markers 22: 175-181, 2006.

26. Lehmann F, Lacombe D, Therasse P and Eggermont AMM: Integration of translational research in the European Organization for Research and Treatment of Cancer Research (EORTC) clinical trial cooperative group mechanisms. J Transl Med 1: 2-5, 2003.

27. Krishnan K, Khanna C and Helman LJ: The molecular biology of pulmonary metastasis. Thorac Surg Clin 16: 115-124, 2006.

28. Harrell JC, Dye WW, Harvell DM, Pinto M, Jedlicka P, Sartorius CA and Horwitz KB: Estrogen insensitivity in a model of estrogen receptor positive breast cancer lymph node metastasis. Cancer Res 67: 10582-10591, 2007.

29. Rajput A, Dominguez San Martin I, Rose R, Beko A, Levea C, Sharratt E, Mazurchuk R, Hoffman R, Brattain MG and Wang J: Characterization of HCT 116 human colon cancer cells in an orthotopic model. J Surg Res (In press).

30. Bruell D, Bruns CJ, Yezhelyev M, Huhn M, Müller J, Ischenko I, Fischer R, Finnern R, Jauch KW and Barth S: Recombinant anti-EGFR immunotoxin 425( $\mathrm{scFv}$ )-ETA' demonstrates antitumor activity against disseminated human pancreatic cancer in nude mice. Int J Mol Med 15: 305-313, 2005.

31. Buijs JT, Henriquez NV, van Overveld PG, van der Horst G, Que I, Schwaninger R, Rentsch C, Ten Dijke P, Cleton-Jansen AM, Driouch K, Lidereau R, Bachelier R, Vukicevic S, Clézardin P, Papapoulos SE, Cecchini MG, Löwik CW and van der Pluijm G: Bone morphogenetic protein 7 in the development and treatment of bone metastases from breast cancer. Cancer Res 67: 8742-8751, 2007.

32. Bertrand Y, Demeule M, Michaud-Levesque J, Béliveau R: Melanotransferrin induces human melanoma SK-Mel-28 cell invasion in vivo. Biochem Biophys Res Commun 353: 418-223, 2007.

33. Miller FR: Immune mechanisms in the sequential steps of metastasis. Crit Rev Oncog 4: 293-311, 1993.

34. Weiss L and Glaves D: Cancer cell damage at the vascular endothelium. Ann NY Acad Sci 416: 681-692, 1983. 